Evidence of Transformation

Bursts During Thermal Cycling of a Pu-Ga Alloy

K. J. M. Blobaum, C. R. Krenn, J. N. Mitchell, J. J. Haslam, M. A. Wall, T. B. Massalski, A. J. Schwartz

February 11, 2005

Metallurgical and Materials Transactions A 
This document was prepared as an account of work sponsored by an agency of the United States Government. Neither the United States Government nor the University of California nor any of their employees, makes any warranty, express or implied, or assumes any legal liability or responsibility for the accuracy, completeness, or usefulness of any information, apparatus, product, or process disclosed, or represents that its use would not infringe privately owned rights. Reference herein to any specific commercial product, process, or service by trade name, trademark, manufacturer, or otherwise, does not necessarily constitute or imply its endorsement, recommendation, or favoring by the United States Government or the University of California. The views and opinions of authors expressed herein do not necessarily state or reflect those of the United States Government or the University of California, and shall not be used for advertising or product endorsement purposes. 


\title{
Evidence of transformation bursts during thermal cycling of a Pu-Ga alloy
}

\author{
KJM Blobaum, ${ }^{1}$ CR Krenn, ${ }^{1}$ JN Mitchell, ${ }^{2}$ JJ Haslam,,${ }^{1}$ MA Wall, ${ }^{1}$ TB Massalski, ${ }^{3}$ AJ Schwartz ${ }^{1}$ \\ ${ }^{1}$ Lawrence Livermore National Laboratory, Livermore, CA 94550 \\ ${ }^{2}$ Los Alamos National Laboratory, Los Alamos, NM 87545 \\ ${ }^{3}$ Carnegie Mellon University, Pittsburgh, PA 15213
}

\begin{abstract}
The thermodynamics and kinetics of the fcc (delta) to monoclinic (alpha-prime) phase transformation and its reversion in a plutonium-gallium alloy have been studied using differential scanning calorimetry, resistometry, and dilatometry. Under ambient conditions, the delta phase is metastable in a Pu-2.0 at\% Ga alloy. Thermal cycling to below the ambient temperature results in a partial transformation to the alpha-prime phase; this transformation is compositioninvariant and exhibits martensitic behavior. Because this transformation results in an unusually large $25 \%$ volume contraction that cannot be fully accommodated by purely elastic adjustments, the transformation mode is expected to involve burst formation of individual alpha-prime particles. However, upon cooling, these individual bursts were not resolved by the above techniques, although signals corresponding to the overall accumulation of many alpha-prime particles were observed. On the other hand, upon heating, signals from differential scanning calorimetry, resistometry, and dilatometry showed a series of discrete changes occurring in periodic increments beginning at approximately $32^{\circ} \mathrm{C}$. These features correspond to the cooperative reversion of many alpha-prime particles to the delta phase; they appear to be the result of an interplay between the autocatalytically driven reversion of a cascade of individual martensite units, and self-quenching caused by small changes of temperature and/or stress accompanying each individual transformation burst. The heat of the delta/alphaprime transformation is estimated to be about $+4 \mathrm{~kJ} / \mathrm{mole}$.
\end{abstract}




\section{Introduction}

At ambient pressures, unalloyed plutonium exhibits six equilibrium solid phases (monoclinic $\square$, body-centered monoclinic $\square$, face-centered orthorhombic $\square$ face-centered cubic ५, body-centered tetragonal $\square$, and body-centered cubic $\square$. Early researchers in the United States and Europe found that when plutonium was alloyed with small amounts of specific solutes, such as gallium or aluminum, the $\square$ phase could be retained at room temperature after cooling. The resulting proposed $\mathrm{Pu}$-rich portion of the $\mathrm{Pu}-\mathrm{Ga}$ phase diagram is shown in Figure 1a. ${ }^{1-3}$ Russian scientists, on the other hand, proposed a phase diagram with a eutectoid decomposition of $\square$ into $\square+\mathrm{Pu}_{3} \mathrm{Ga}$ (cubic or tetragonal, depending on temperature) at $97^{\circ} \mathrm{C}$ (Figure 1b). ${ }^{3,4}$ The Russian diagram is now generally accepted as the more likely "equilibrium" phase diagram (note that because plutonium continuously undergoes radioactive decay, the system never attains true thermodynamic equilibrium). The kinetics of the eutectoid reaction, however, are expected to be exceedingly slow, involving times of the order of 10,000 years. ${ }^{3}$ Thus, the alloyed $\square$ phase, although metastable, can be retained at room temperature practically indefinitely. ${ }^{3,5}$

When the retained metastable $\square$ phase is cooled to subambient temperatures, it partially transforms via a martensitic transformation ${ }^{6,7}$ to a metastable $\square$ ' phase with the transformation temperature dependent on composition. The $\square$ ' phase is an extension of the monoclinic $\square$ phase of pure $\mathrm{Pu}$ with $\mathrm{Ga}$ trapped in the lattice, such that local distortions occur. Given sufficient time and temperature, it is likely that the Ga solute atoms diffuse locally, and they may show a preference for the number 8 lattice site. This may result in relaxation of the $\square$ ' phase to the unexpanded $\square$-phase. ${ }^{8}$ The lattice remains alloyed in the $\square$-phase unless the solute Ga atoms 
leave the lattice; this process is not likely to occur at temperatures below room temperature under ambient pressures. ${ }^{8}$ The lattice parameters of the $\square$ and $\square$ ' phases are similar, but they increase slightly with Ga contents. ${ }^{8}$ The martensitic transformation to $\square$ ' can continue isothermally at temperatures below an initial onset temperature, which we refer to here as the martensite burst temperature, $M_{b}$. Unlike athermal martensitic transformations that exhibit essentially timeindependent kinetics, the amount of $\square^{\prime}$ (martensite) formed from $\square$ can be represented as a function of isothermal hold times. As a result, the kinetics of the transformation can be expressed as a C-shaped curve in a time-temperature-transformation (TTT) diagram. ${ }^{9}$

The $\square \rightarrow \square$ ' transformation has several unusual and intriguing characteristics. For example, the transformation does not proceed to completion upon continuous cooling; in a Pu-2.0 at $\%$ Ga alloy, the maximum amount of transformation to $\square$ ' is about $30 \%$. The transformation involves an extremely large volume contraction of about $25 \%$ with an accompanying change of about $45 \%$ in electrical resistivity. Upon heating, $\square$ ' reverts to $\square$, but the temperature span of the thermal hysteresis is quite large, approximately $150^{\circ} \mathrm{C}$, depending on the alloy composition. Recent work indicates that this reversion exhibits an unusual succession of sharp peaks in differential scanning calorimetry (DSC) scans, ${ }^{10-12}$ and corresponding discrete, incremental steps in dilatometry ${ }^{13}$ and resistometry ${ }^{12}$ plots, which suggest autocatalytic burst martensite events. It is the nature of the $\square \rightarrow \square$ ' martensitic transformation, and its corresponding reversion, that we focus on here.

The diagram in Figure 2, which maps the stable or metastable phases expected to be present in the Pu-Ga system if long-range diffusion is excluded at low temperatures, shows how the transformation hysteresis varies with Ga concentration. All such metastable phases ( $\square$ matrix or martensites) retained or formed below the temperatures where the diffusional activity is 
essentially frozen represent the condition of 'constrained equilibrium'. The 'true equilibrium,' as dictated by the Third Law of Thermodynamics, requires the entropy of mixing to become zero at $0 \mathrm{~K}\left(-273.15^{\circ} \mathrm{C}\right)$. Hence, the true equilibrium allows only a mixture of pure $\mathrm{Pu}$ and ordered $\mathrm{Pu}_{3} \mathrm{Ga}$ to be present in the low-Ga composition range at very low temperatures.

Here, we use DSC, dilatometry, and resistometry to examine the $\square \square \square^{\prime}$ transformations in detail, and we describe how these transformations proceed via a burst mode. Upon cooling, $\square^{\prime}$ units form independently and their growth is nearly instantaneous. These individual bursts, however, are not resolved by the techniques used here. The reversion proceeds via a cooperative burst mode, where the reversion of many $\square$ ' particles occurs autocatalytically as a cascade. These cooperative bursts are observed in the techniques used here. This behavior is concluded to be the result of an interaction between the autocatalytic nature of the burst reversion process and the quenching of the reaction following each cascade due to small changes of temperature or stress which add a positive contribution to the free energy and reduce the driving force.

\section{Experimental}

A Pu-2.0 at\% Ga alloy was used in all experiments. For the DSC and resistometry experiments, samples were initially annealed at $440^{\circ} \mathrm{C}$ for 12 hours to produce a stable distribution of single-phase $\square$ throughout the sample. The average grain size was $\sim 25 \mu \mathrm{m}$. After cutting the samples with a diamond saw, the surface oxide was removed by mechanical polishing, and the sample was then annealed at $175^{\circ} \mathrm{C}$ for 30 minutes to revert any $\square$ ' that may have formed on the surface during polishing.

Resistivity experiments were carried out on discs ( $2.8 \mathrm{~mm}$ diameter, $150 \mu \mathrm{m}$ thick, $\sim 17$

$\mathrm{mg}$ ) in a vacuum chamber with a base pressure of $10^{-5}$ torr. A liquid helium cryostat and 
accompanying heaters allowed thermal cycling of the sample between $-200^{\circ} \mathrm{C}$ and $350^{\circ} \mathrm{C}$ at constant rates of 0.3 to $5^{\circ} \mathrm{C} / \mathrm{min}$. Resistance of the sample was measured using the four-point probe technique (a.k.a. the Kelvin probe). The contacts were $0.254 \mathrm{~mm}$ diameter copper wires running in parallel across the surface, with the outer two wires sensing current and the inner two wires sensing voltage. ${ }^{14}$

DSC samples were $2.8 \mathrm{~mm}$ diameter cylinders with two opposing flats running parallel to the major axis. The purpose of the flats was to provide better thermal contact between the sample and the pan. The cylinders were about $3 \mathrm{~mm}$ long and weighed approximately $230 \mathrm{mg}$. A Perkin-Elmer "Diamond" power-compensation DSC with liquid nitrogen cooling was used to measure heats and temperatures of transformation during thermal cycles. The instrument was calibrated with adamantane (solid-solid transformation at $-64.53^{\circ} \mathrm{C}, \Delta H=24.78 \mathrm{~J} / \mathrm{g}$ ), ${ }^{15}$ indium (solid to liquid transformation at $156.6^{\circ} \mathrm{C}, \Delta H=28.45 \mathrm{~J} / \mathrm{g}$ ), and zinc (solid to liquid transformation at $419.47^{\circ} \mathrm{C}, \Delta H=108.37 \mathrm{~J} / \mathrm{g}$ ). Samples were contained in gold-lined stainless steel pans sealed with gold-plated copper gaskets. These pans can withstand $150 \mathrm{~atm}$ of pressure at $400^{\circ} \mathrm{C}$ and were deemed acceptable for safely containing radioactive materials. The purge gas was a mix of $90 \% \mathrm{Ne} / 10 \% \mathrm{He}$, which can be used between $-176^{\circ} \mathrm{C}$ and $585^{\circ} \mathrm{C} .{ }^{16}$ In the DSC thermal cycling experiments described here, the sample was cooled from $25^{\circ} \mathrm{C}$ to $-160^{\circ} \mathrm{C}$, held for 1 minute, heated to $350^{\circ} \mathrm{C}$, held for 1 minute, and then cooled back to $25^{\circ} \mathrm{C}$. Heating and cooling rates were between 1.5 and $20^{\circ} \mathrm{C} / \mathrm{min}$.

Due to the practical and safety-related issues involved with removing a plutonium alloy specimen from the differential scanning calorimeter, a single sample was cycled repeatedly for the experiments described here. Prior work with resistometry ${ }^{14}$ and DSC samples showed that the $\square \square$ ' transformations are highly reproducible, provided the sample is re-annealed at $375^{\circ} \mathrm{C}$ for 
8 hours after each run. ${ }^{*}$ Since the sample could not be removed after each run to provide a baseline scan of the empty sample pans, an extrapolated baseline was used. For the cooling portion of the DSC scans, a line was fitted to the heating data in the temperature range of interest and it was subtracted as the baseline. For the heating data, a third-order polynomial was fitted to the cooling data in the same temperature range, and this was subtracted as the baseline. In both cases, a second line was also subtracted to correct for the slope and to make the peaks in the data more obvious on the plots. While we recognize that this technique cannot provide accurate heat capacity data, it is a consistent method for analyzing the data. In the work reported here, the qualitative features of the observed spikes are the primary focus. Comparison of unsubtracted data and data analyzed with the technique described here shows no significant qualitative differences.

For the dilatometry experiments, a Pu-2.0 at $\%$ Ga alloy was homogenized at $420^{\circ} \mathrm{C}$ for 100 hours, cold rolled to $91 \%$ reduction, and annealed at $350^{\circ} \mathrm{C}$ for 15 minutes. The average grain size is $17 \mu \mathrm{m}$, and the Ga distribution is very uniform. Optical microscopy and dilatometry

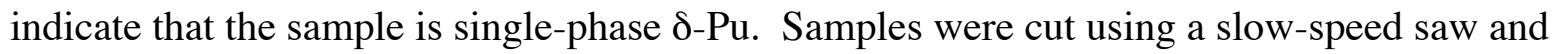
opposite surfaces were ground parallel and polished. Final samples weighed $200-400 \mathrm{mg}$ and thicknesses were 1-2 mm. Prior to cooling the samples in the dilatometer, some of the samples were heated to $200^{\circ} \mathrm{C}$ to transform any mechanical $\mathrm{C}$ ' produced during sample preparation. Dilatometry was performed using a Netzsch $402 \mathrm{C}$ dilatometer with a low-temperature furnace and quartz glass sample holders and pushrods. Cooling and heating rates were 1,5, and $10^{\circ} \mathrm{C} /$ minute. The furnace was evacuated and backfilled with high-purity He gas, and a gas flow

\footnotetext{
*Actually, before a run was attempted following the anneal at $375^{\circ} \mathrm{C}$, each sample rested in the calorimeter for some time at ambient temperatures. This really amounts to another anneal prior to the cooling cycle and we will show in another paper ${ }^{17}$ that this "conditioning" is important in determining the ultimate percentage of the $\square$ '-phase that will be obtained.
} 
rate of $30 \mathrm{~mL} / \mathrm{min}$ was used during all experiments. Analyses of NIST-origin stainless steel, copper, and borosilicate glass standards were within $2 \%$ of accepted values.

\section{Results}

\section{Transformations during thermal cycling}

In a Pu-2.0 at\% Ga alloy, the $\square \rightarrow \square^{\prime}$ transformation and the $\square^{\prime} \rightarrow \square$ reversion are typically the only transformations observed between $-160^{\circ} \mathrm{C}$ and $375^{\circ} \mathrm{C}$. Figure 3 is a plot of sample resistance vs. temperature for seven thermal cycles at $1.5^{\circ} \mathrm{C} / \mathrm{min}$. During these cycles, the sample is cooled from $25^{\circ} \mathrm{C}$ to $-196^{\circ} \mathrm{C}$, heated to $350^{\circ} \mathrm{C}$, and then cooled back to $25^{\circ} \mathrm{C}$. The resistivity of the $\square$ ' phase is about $45 \%$ higher than that of the $\square$ phase, and the onset of the $\square \rightarrow \square$ transformation $\left(M_{b}\right)$ is distinguished by a steep rise in the resistance at $-123^{\circ} \mathrm{C}$. Upon heating, the $\square^{\prime} \rightarrow \square$ reversion start $\left(R_{s}\right)$ is observed as a gradual decrease in resistance beginning at approximately $50^{\circ} \mathrm{C}$ at $0.3^{\circ} \mathrm{C} / \mathrm{min}, 47^{\circ} \mathrm{C}$ at $1.5^{\circ} \mathrm{C} / \mathrm{min}$, and $32^{\circ} \mathrm{C}$ at $5^{\circ} \mathrm{C} / \mathrm{min}$. The highly reproducible temperature hysteresis of about $150^{\circ} \mathrm{C}$ is large compared to most other solid-state transformations.

Using dilatometry data, we can measure the amount of transformation during the thermal cycles. For these measurements, the following two assumptions are made: 1.) Upon cooling, there is no transformation prior to $M_{b}$. 2.) The volume difference between $\square$ and $\square$ ' is $25 \%$, and the length difference is $8 \%$, assuming there are no textural orientation effects. We estimate that the maximum amount of transformation to $\square$ ' during continuous cooling is $20 \%$. Similar results have been obtained with $\mathrm{x}$-ray diffraction ${ }^{14}$ and quantitative metallography.

The Pu-2.0 at\% Ga alloy was also thermally cycled in the DSC apparatus. Cooling and heating portions of DSC scans at 1.5, 5, 10, and $20^{\circ} \mathrm{C} / \mathrm{min}$ are shown in Figures 4 and 5, 
respectively. In each figure, both the unsubtracted (raw) data and the subtracted data are shown. The $M_{b}$ and $R_{s}$ temperatures depend on heating rate; $M_{b}$ ranges from $-97^{\circ} \mathrm{C}$ at $1.5^{\circ} \mathrm{C} / \mathrm{min}$ to $-107^{\circ} \mathrm{C}$ at $20^{\circ} \mathrm{C} / \mathrm{min}$ and $R_{s}$ ranges from $61^{\circ} \mathrm{C}$ at $1.5^{\circ} \mathrm{C} / \mathrm{min}$ to $33^{\circ} \mathrm{C}$ at $20^{\circ} \mathrm{C} / \mathrm{min}$. These temperatures correlate well with $M_{b}$ and $R_{s}$ temperatures measured with resistometry. The sharp peaks evident in the heating data will be analyzed in the following section.

The $M_{b}$ temperature of the $\mathrm{Pu}-2.0$ at $\%$ Ga alloy as measured by dilatometry varies depending on the thermal profile of the experiment. For the samples heated to $200^{\circ} \mathrm{C}$ prior to cooling to $-165^{\circ} \mathrm{C}, M_{b}$ is $-145.0 \pm 0.1^{\circ} \mathrm{C}$. The samples cooled to $-165^{\circ} \mathrm{C}$ directly from $25^{\circ} \mathrm{C}$ yield a higher $M_{b}$ of $-134.6 \pm 2.7^{\circ} \mathrm{C}$. Cooling rates for all of these experiments were $5^{\circ} \mathrm{C} / \mathrm{min}$. The calculated amount of transformation ranges from 10-20\% \', and was found to be a function of the amount of time spent at $-165^{\circ} \mathrm{C}$. The dilatometry samples are expected to have a lower $M_{b}$ temperature than the DSC and resistometry samples because the former were homogenized for longer periods of time. In the less homogeneous DSC and resistometry samples, regions of low gallium concentration will transform at higher temperatures than high gallium regions (see Figure 2). The well-homogenized dilatometry samples, however, are unlikely to involve such low gallium regions, and thus, they have a lower overall $M_{b}$ temperature. Additionally, dilatometry data also indicate that heating rate affects $R_{s}$ temperatures, with a systematic decrease from $55.7^{\circ} \mathrm{C}$ to $47.7^{\circ} \mathrm{C}$ to $27.4^{\circ} \mathrm{C}$ as rates increase from $1^{\circ} \mathrm{C} / \mathrm{min}$ to $5^{\circ} \mathrm{C} / \mathrm{min}$ to $10^{\circ} \mathrm{C} / \mathrm{min}$, respectively. The systematic decrease in the $R_{s}$ temperature with increasing heating rates observed in both DSC and dilatometry experiments is not fully understood and will be the subject of future investigations.

2. The progression of the $\square^{\prime} \rightarrow \square$ reversion in discrete increments 
Inspection of the resistometry data in the region corresponding to the $\square$ ' $\rightarrow$ reversion reveals that the resistance decreases incrementally in discrete steps, while the temperature increases smoothly. When the resistometry data is differentiated with respect to temperature $(d \square / \mathrm{T})$ and plotted versus temperature, periodic spikes between $25^{\circ} \mathrm{C}$ and $125^{\circ} \mathrm{C}$ are obvious. Figure 6 shows both the undifferentiated and differentiated data obtained at three heating rates. Noise is present in the differentiated data, but the pattern clearly changes near $50^{\circ} \mathrm{C}$, which is slightly above the $R_{s}$ temperature observed in the undifferentiated data (Figure 3).

DSC data also indicate periodic sharp peaks accompanying the $\square \rightarrow \square$ reversion. In the continuous heating scans at $1.5,5$, and $10^{\circ} \mathrm{C} / \mathrm{min}$, the reversion is marked by a series of sharp peaks with a broad endothermic envelope, as seen in Figure 5. As the heating rate increases from 1.5 to $10^{\circ} \mathrm{C} / \mathrm{min}$, the number of sharp peaks decreases and they become less distinct. At $20^{\circ} \mathrm{C} / \mathrm{min}$, the transformation is characterized by a relatively smooth endotherm with some lowintensity sharp peaks on the high temperature side.

Like the resistometry data and the DSC runs, the dilatometry data also show that the length change associated with the $\square^{\prime} \rightarrow \square$ reversion occurs in discrete steps as the temperature increases continuously (Figure 7). A plot of $d \mathrm{~L} / d$ (time) versus temperature shows a series of periodic spikes (Figure 7), similar to what is seen in the plot of $d \square d$ T (Figure 6). The dilatometry data also correlate well with the DSC data in that the number of peaks is greater and the incremental changes during the reversion are more discrete when the heating rate is slower.

\section{Periodicity of the incremental changes observed during the $\square^{\prime} \rightarrow \square$ reversion}

In all three of the characterization techniques used here, the discrete incremental changes in resistivity, length, and heat flow associated with the $\square$ ' $\rightarrow$ reversion are nearly periodic with 
respect to temperature. Furthermore, the period of the events is essentially constant at all heating rates and with all three characterization techniques.

To study the periodicity of the steps and spikes, we define a period $(\square)$ as the temperature difference between two adjacent peaks. The most intense peak is designated zero; peaks to the left of zero progress sequentially with negative numbers, and, conversely, peaks to the right of zero progress sequentially with positive numbers. This nomenclature is illustrated on a DSC thermogram in Figure 8.

In Figure 9, $\square$ is plotted as a function of peak number for all three techniques and at several heating rates. The most notable feature of the data is that the difference between the largest and smallest $\square$ values is only 3.5 degrees. There is no systematic variation in $\square$ with either heating rate or analysis technique. To examine the range of $\square$ that can occur at a given heating rate, three DSC scans at $1.5^{\circ} \mathrm{C} / \mathrm{min}$ and two scans at $5^{\circ} \mathrm{C} / \mathrm{min}$ are plotted in Figure 9a. These data give an indication of the scatter expected in $\square$ due to variations in the progression of the $\square$ ' $\rightarrow \square$ reversion in each experimental run. Note that nearly all of the $\square$ values obtained during thermal cycles of the $\mathrm{Pu}-2.0$ at\% Ga alloy at all heating rates and with all three techniques fall within the range of these three $1.5^{\circ} \mathrm{C} / \mathrm{min} \mathrm{DSC}$ scans. Some data indicate that the separations between the burst occurrences increase slightly as the reaction progresses; this suggests a decrease in transformation rate as the last $\square$ ' particles revert to the $\square$ phase.

\section{Reproducibility of the transformation and reversion}

Thermal cycling of the Pu-Ga alloys show excellent reproducibility; both the amount of transformation and the transformation temperatures are consistent from scan to scan and among the three characterization techniques. In DSC and resistometry experiments, a single $\mathrm{Pu}-\mathrm{Ga}$ 
sample can be cycled many times, with a high temperature anneal between cycles. Following the anneals, $M_{b}, R_{s}$, and the amount of transformation were highly reproducible from scan to scan. In contrast, dilatometry samples were only cycled once. It has been shown previously that consecutive thermal cycles with no anneal between cycles progressively displace $M_{b}$ to lower temperatures and decrease the amount of transformation. ${ }^{8,13}$

\section{The enthalpy of the phase transformations}

The integrated area of the DSC peaks was used to calculate the heat absorbed or released in the transformations (heats of transformation, $\Delta H_{t}$ ). The sharp peaks in the slow heating scans make accurate peak integration difficult, so data from the scan at $20^{\circ} \mathrm{C} / \mathrm{min}$ were used to calculate $\Delta H_{t}$ values. Assuming a $20 \%$ transformation, $\square H_{t}^{\square[\square[}=-0.85 \pm 0.08 \mathrm{~kJ} / \mathrm{mole}$ and $\square H_{t}^{\square \square \square}=+4.1 \pm 0.2 \mathrm{~kJ} / \mathrm{mole}$

It is notable that the enthalpies calculated for the transformation and reversion differ by a factor of 4.8. We attribute this difference to inaccuracies in the measurement of heat released by the formation of $\square^{\prime}$ during the cooling portion of the DSC scans. Previous work ${ }^{8}$ and resistometry data indicate that, while most of the transformation to $\square$ ' occurs during cooling, some additional $\square$ ' forms during heating. Such additional transformation is evident in resistometry scans; upon heating from the minimum temperature $\left(-196^{\circ} \mathrm{C}\right)$, the heating curve does not exactly trace the expected curve based on the amount of $\square$ ' formed on cooling. According to the TTT diagrams published by Orme and Faiers, ${ }^{9}$ this is not unexpected. At low temperatures, the $\square \rightarrow \square$ ' transformation ceases, or becomes extremely slow. Upon re-heating, however, additional transformation may occur as the TTT diagram is traversed in the opposite direction. In the DSC scans, however, we do not observe additional transformation to $\square$ ' on 
heating, and thus cannot quantify any additional heat released. It is likely that any additional $\square$ ' formation during heating occurs over a wide temperature range, contributing to a broad peak that is indistinguishable from the baseline. Another reason for the discrepancy between the $\Delta H \mathrm{~s}$ calculated for the forward and reverse reactions is that the exothermic peak corresponding to $\square$ ' formation does not return to the baseline before the lower temperature limit of the DSC is reached (Figure 4a). The peak is asymmetric with a sharp leading edge, indicative of a transformation that initiates quickly, but the trailing edge of the peak tapers off slowly and does not return to the baseline. Thus, it is likely that the transformation would continue if the temperature could be decreased further, or if the sample was held isothermally. Because the peak does not return to the baseline, the calculated area can be significantly smaller than it would be if the peak returned to a baseline level. Therefore, we believe that the measured value of $-0.85 \mathrm{~kJ} / \mathrm{mole}$ is a lower limit for $\square H_{t}^{\square \square \square}$. The value of $\square H_{t}^{\square \square \square}$ measured for the reversion $(+4.1 \mathrm{~kJ} / \mathrm{mole})$ is a more accurate value for the enthalpy of the $\square \square$ ' transformations.

\section{Discussion}

\section{The nature of martensitic transformations}

In light of the unusual martensitic behaviors in a Pu-2.0 at\% Ga alloy, we discuss here briefly what is known about martensitic transformations in general. Regarding the mechanism of the transformation, two characteristic types of martensite formation modes have been reported in the literature: thermoelastic and burst. ${ }^{18,19}$ Thermoelastic martensites can occur when relatively small transformation shape and volume strains are involved and these strains can be almost entirely accommodated by elastic deformation of the matrix. Once nucleated, they can proceed smoothly with changes in temperature, or at a constant temperature with changes of applied 
stress (typically below the martensite start temperature, $M_{s}$ ). Conversely, burst martensite modes occur when the transformation generates significant matrix strains which must be accommodated with plastic deformation or twinning. Individual martensitic grains form instantly (at the speed of sound in the matrix ${ }^{20-22}$ ) when the free energy driving force becomes sufficient (below a temperature sometimes referred to as $M_{b}$ ) to overcome matrix strains. The interaction between the growing martensite crystals and their corresponding plastic zones in the matrix can influence both the kinetics of the transformation and its morphology. ${ }^{18,23,24}$ Burst transformations may also be inhibited by adiabatic heating (or cooling) of the sample caused by the transformation itself, as noted in the literature by Brook and Entwisle, ${ }^{25}$ Entwisle, ${ }^{26}$ and Raghavan. ${ }^{27}$ In some nonferrous alloys, martensite formation can occur by both the thermoelastic mode (below $M_{s}$ ) and the burst mode (below $M_{b}$ ) in the same alloy, depending on the speed of cooling and other experimental conditions. $^{24}$

Metallographic observations using cinematographic techniques under an optical microscope can reveal 'burst events' related to the formation of individual martensitic units. ${ }^{24}$ Such details may not be resolvable with techniques such as differential scanning calorimetry, resistometry and dilatometry, that respond to the sum-total of all the changes occurring in the sample at any given time. In such a case, the term 'burst' may be used to describe a mode in which a cascade of individual martensite events is triggered autocatalytically ${ }^{26,27}$ or occurs cooperatively. ${ }^{28}$ Thus, the overall formation rate of the martensite product may rapidly increase and then decline, and may continue to oscillate as additional cascades are triggered. When the volumetric effects become substantial, as in Pu-Ga alloys, it appears that the $M_{s}$ for possible thermoelastic growth is not practically feasible and the $M_{b}$ now appears to be conveniently referred to as $M_{s}$ by researchers in this field. 
For the Pu-Ga system, the thermoelastic growth mode is less likely than the burst mode because the combined elastic and plastic work for the burst event is smaller than the elastic work for the thermoelastic growth, given the same free energy drop. Without plasticity, the large volume change between $\square$ and $\square$ ' ( 25\%) could result in elastic stresses exceeding several GPa. A simple analysis of an isolated spherical $\square$ ' particle in a $\square$ matrix results in an elastic misfit energy that approaches $6 \mathrm{~kJ} /$ mole. $^{29}$ However, when plastic flow is allowed (assuming an 80 MPa yield strength for $\square^{30}$ ), the misfit energy drops to a more reasonable value of $0.7 \mathrm{~kJ} / \mathrm{mole}$. Similar results are obtained for more realistically-shaped particles. Since plastic work is involved in $\square^{\prime} / \square$ phase transformations (as evidenced by increased dislocation densities in $\square$ close to $\square$ ' particles $\left.{ }^{31}\right)$, it must proceed by the burst mode. In fact, the burst mode of the $\square \rightarrow \square$ ' transformation has already been demonstrated by acoustic emission experiments ${ }^{7}$ (note that the phase denoted as $\square$ in Heiple and Carpenter's paper is referred to as $\square$ ' here).

Martensitic transformations can be further categorized by their kinetics, which can be described as athermal or isothermal. ${ }^{27}$ Athermal kinetics, where the overall amount of martensite formed is only a function of temperature change and is not time-dependent, are the most common. These transformations usually have well-defined martensite start $\left(M_{s}\right)$ and martensite finish $\left(M_{f}\right)$ temperatures. Isothermal kinetics, on the other hand, can be studied at a particular constant temperature as a function of time. In the isothermal case, individual martensite particles tend to grow at a rate characteristic of the speed of sound in the transforming matrix, but the overall amount of martensite forming can have a time-dependent component. As a result, timetemperature-transformation (TTT) diagrams can be constructed to show the conditions required to achieve a desired amount of transformation. In most isothermal TTT studies, a narrow temperature range can be identified at which the transformation rate is highest, and this is often 
called the "nose" or the "knee," as in typical diffusion TTT diagrams. Interestingly, the $\square \rightarrow \square$ ' isothermal martensitic transformation in many $\mathrm{Pu}-\mathrm{Ga}$ alloys suggests two $\mathrm{C}$-shaped noses, indicating the possibility of different mechanisms, or different phase formations, being involved. ${ }^{5,9}$

For isothermal martensites, a significant incubation time may be required before transformation commences, particularly at temperatures far above or below the nose. Observation of an incubation time for isothermal martensites suggests that these transformations have both thermally activated and displacive components.

\section{Burst mode of the $\square$ ' $\rightarrow \square$ reversion}

The most intriguing features of $\square^{\prime} / \square$ transformations in Pu-Ga alloys reported here are the discrete incremental changes observed with resistometry, dilatometry, and differential scanning calorimetry that correspond to the $\square$ ' $\rightarrow \square$ reversion during continuous heating. We first consider similar observations in phase transformations reported in the literature. The steps observed in the dilatometry plots reported here bear a strong resemblance to dilatometry plots of "burst transformations" in high-nickel steels reported by Brook and Entwisle. ${ }^{25}$ In this case, a $0.5 \% \mathrm{C}-24 \% \mathrm{Ni}$ steel was cooled and underwent a martensitic transformation in which cascades of particles transformed autocatalytically, resulting in discrete, incremental increases in sample length. Although sharp peaks in DSC scans are certainly not common in the literature, they are not unprecedented. Kitching et al. reported a burst cascade behavior in the DSC signal resulting from the $\square$ ' $\rightarrow \square$ reversion in a Pu-1.89 at\% Ga alloy, ${ }^{11}$ and Mitchell et al. showed similar behavior during the $\square \rightarrow \square$ transformation in pure Pu. ${ }^{13}$ Interestingly, the sharp peaks reported by Kitching are periodic, ${ }^{11}$ like those reported here, but Mitchell ${ }^{13}$ and Schwartz ${ }^{32}$ report that sharp 
peaks attributed to the $\square \rightarrow \square$ transformation can be periodic (with an identifiable $\square$ ), or random, depending on the cooling rate. In a very different material, methylammonium hexachlorotellurate (IV) $\left(\left(\mathrm{CH}_{3} \mathrm{NH}_{3}\right)_{2}\left[\mathrm{TeCl}_{5}\right]\right)$, Onoda et al. ${ }^{33}$ used differential thermal analysis to observe randomly-spaced sharp peaks resulting from a phase transformation. These sharp peaks were interpreted as evidence of a martensitic transformation.

In the case of the $\square^{\prime} \rightarrow \square$ reversion in Pu-Ga alloys, we would like to answer a series of questions relating to the source of the observed discrete, incremental changes: 1) Are these features real, or are they experimental artifacts? 2) Are these features significantly influenced by material microstructure? And, 3) since the transformation produces both heat and residual stress fields, how do heat flow and stress affect transformation rates?

We are confident that the experimentally observed incremental changes are caused by real variations in the transformation rate, and not by any sort of experimental artifact, because we see correlated variations in the transformation rate using three different experimental techniques. It is important to note that it is the transformation rate, not the progress of the transformation or reversion, that oscillates. An oscillation in the transformation progress would imply that products are alternately formed and consumed. Evidence of this is not observed in dilatometry, resistometry, or DSC data. Rather, the rate of the transformation oscillates by alternately speeding up and then slowing down. A true oscillation in the transformation rate implies that there is a coupling between some mechanism, or set of mechanisms, that accelerates the transformation during the rising edge of the burst and a second mechanism or set of mechanisms during the falling edge that decelerates the transformation. For the purposes of this paper, we generically refer to mechanisms that accelerate the transformation as "autocatalytic" and mechanisms that decelerate the transformation as "self-quenching." However, these 
autocatalytic and self-quenching mechanisms may still be driven locally by variations in temperature, or elastic stress, or by details of the experimental configuration.

Feedback between the temperature control circuits and the rapid absorption of heat during the transformation is a plausible scenario in which bursts not caused by the transformation could be observed. Plutonium is a likely candidate for this feedback because of its low thermal conductivity $\left(8.37 \mathrm{~W} / \mathrm{K} \cdot \mathrm{m}\right.$ for the $\square$ phase at $298 \mathrm{~K},{ }^{34}$ as compared to $401 \mathrm{~W} / \mathrm{K} \cdot \mathrm{m}$ for copper at $300 \mathrm{~K}^{35}$ ). The period of the bursts, however, could be a function of the design of the thermal controller and the mass and surface area of the plutonium specimens. However, since a similar period is seen using three experimental techniques employing different control systems, sample geometries (and masses ranging from $17 \mathrm{mg}$ to $400 \mathrm{mg}$ ), and heater configurations, instrumental feedback as the main cause cannot alone be a reasonable explanation for the periodicity of the bursts.

On the other hand, both thermal and/or stress induced autocatalysis and self-quenching are very likely causes of the observed bursts. An initial reversion event changes its thermal environment and surrounding stress state, and thus may autocatalyze other events along some interconnected path, resulting in a cascade of reverting martensite particles. As the endothermic reaction proceeds, heat is absorbed, which can locally or globally lower the sample temperature. If the change in temperature is significant, the sample temperature could fall below what is required to sustain reversion, and the reversion could abruptly stop. Because the sample is subjected to a well-controlled constant heating rate, however, the instrument promptly re-heats the sample and the reversion commences again. The result is a series of bursts, each corresponding to the initiation of the reversion and the accompanying self-quenching. Incidentally, Brook and Entwisle ${ }^{25}$ noted a marked rise in the specimen temperature during 
autocatalytic burst events in a martensitic steel. They hypothesized that these temperature fluctuations temporarily quenched the transformation. The step-wise transformation they observed with dilatometry, however, was not periodic.

The thermal quenching model of the $\square$ ' $\rightarrow \square$ reversion is attractive because it offers a way to explain the striking periodicity of the endothermic bursts. Plausibly, the period might be only a function of the intrinsic thermal properties of plutonium: thermal conductivity and heat of transformation. Because of the limited number of bursts observed, however, local cooling and thermal transport must occur over length scales that are a significant fraction of the specimen size. Again, since a similar number of bursts is observed in three different sample sizes, thermal quenching alone cannot provide a complete explanation.

An alternative (or an additional) mechanism for both autocatalysis and self-quenching is stress, which can raise or lower the activation energy for nucleation and/or growth. The presence of strain in the matrix as a quenching factor in the progress of a martensitic transformation was already suggested by Cech and Turnbull. ${ }^{36}$ Finite-element modeling of elastic/plastic effects in $\mathrm{Pu}-\mathrm{Ga}$ transformations indicates that residual stresses may remain in the $\square$ phase in the region of a reverted $\square^{\prime}$ particle, as shown in Figure $10 .{ }^{12}$ At the tip of the particle, the stresses aid further reversion, but in regions perpendicular to the particle (along the long axis), the stresses retard further transformation. Thus, residual stresses can cause both autocatalysis and self-quenching. One possible scenario in which these effects may result in observable cooperative, autocatalytic bursts begins with a network of $\square$ ' particles reverting cooperatively under the influence of the stress fields near the particle tips. Then, regions perpendicular to the network of initial transformation require additional heating to surmount the energy barriers for transformation, which have been increased by compressive residual stresses. As succeeding sets of particles 
transform, compressive stresses build up further and quench the transformation a multiple of times. This cycle may continue during isochronal (constant heating rate) heating until the temperature is sufficiently high to revert all of the $\square$ ' particles back to the $\square$ phase. Because this stress-driven autocatalytic and self-quenching process is governed by the geometry of the $\square$ ' network, it is unlikely to be influenced greatly by specimen geometry, except perhaps in the extreme case of a thin film whose thickness approaches the dimensions of the grain size.

We conclude that a combination of autocatalysis and self-quenching by the induced stress and temperature fluctuations provides the most likely explanation for the periodic, discrete, incremental changes observed during the $\square^{\prime} \rightarrow \square$ reversion. Each of these features is the result of a cascade of many $\square$ ' particles reverting to $\square$ nearly simultaneously. Each individual martensite unit within the cascade reverts via a burst martensitic mode. The cooperative nature of this reversion and the rapid progress evidenced by the sharp leading edges of the DSC peaks lead us to conclude that the $\square^{\prime} \rightarrow \square$ reversion involves autocatalytic burst martensite behavior.

The observation that the number of DSC peaks during reversion decreases and that the peaks become less distinct as the heating rate increases suggests that the reversion is increasingly more kinetically, rather than thermodynamically (i.e., driving force energy) limited at faster heating rates. If the transformation rate during each cooperative cascade was directly proportional to the amount of superheating, the DSC plots at all heating rates might be expected to show the same number of peaks. At higher heating rates, however, the individual peaks are broader and tend to overlap. At the highest heating rate, there is so much overlap that the peaks are no longer distinct (Figure 5b), but small spikes on the high temperature side of the DSC peak offer evidence of overlapping cascades. 


\section{Comparison of the forward and reverse transformation kinetics}

If a thermally- or stress-driven self-quenching is an accurate explanation for the spikes observed during the $\square^{\prime} \rightarrow \square$ reversion, it would be logical to expect similar spikes during the forward $\square \rightarrow \square$ ' transformation. The forward transformation is exothermic and occurs on cooling; this is precisely the opposite of the reversion, which is endothermic and occurs upon heating. Thus, induced residual stresses and heat release by the forward transformation could quench the reaction, analogous to the quenching observed in the reversion. To understand why bursts are not observed, we need to understand the propagation of both the initial transformation and the reversion. It is reasonable to expect that the transformation mode of the $\square \rightarrow \square$ ' transformation is slower than the reversion because the forward transformation requires nucleation, whereas the $\square^{\prime} \rightarrow \square$ reversion may be assumed to involve only the movement of the $\square^{\prime} / \square$ interface already in existence. In fact, the need for nucleation may cause the formation of the $\square$ ' units during the forward $\square \rightarrow \square$ ' reaction to be a fairly continuous process, not involving specifically cooperative formation leading to cascades. Nucleation difficulties of the $\square$ ' phase, however, are not sufficient to explain why bursts are not observed with the techniques described here during the forward $\square \rightarrow \square^{\prime}$ transformation. After $\square$ ' nucleates, the martensitic growth of each individual unit is nearly instantaneous. Thus, it is likely that each individual $\square$ ' particle generates a burst of heat when it grows, and the large number of extremely small bursts occurring in close temporal proximity, but not necessarily as a cascade, results in a cumulative effect that appears continuous.

Let us consider in more detail the role of nucleation in the forward transformation. The $\square \rightarrow \square$ ' transformation is an isothermal martensitic transformation, ${ }^{6,7}$ and it is known that nucleation is the critical, rate-limiting step in such transformations. ${ }^{37}$ Traditionally, isothermal 
martensite transformations have been studied by quenching and holding isothermally. The continuous cooling and heating experiments described here may nevertheless be regarded as a continuous series of short isothermal holds occurring as a set of continuous steps. In both cases, thermally activated nucleation appears to be the controlling step. Although the growth of individual martensite particles is likely to occur nearly instantaneously, it is the nucleation step that causes the sluggish kinetics of isothermal martensites. Specifically, the TTT diagram for a Pu-1.9 at\% Ga alloy ${ }^{9}$ suggests that an incubation time may be required before transformation begins at any temperature, and, if a sample is cooled rapidly enough, presumably the formation of $\square$ ' can be completely avoided.

Unlike the continuous $\square \rightarrow \square$ ' transformation, the reversion of $\square$ ' to $\square$ upon heating clearly shows discrete, incremental changes in DSC, dilatometry, and resistometry. Since the $\square^{\prime} \rightarrow \square$ reversion only involves moving the $\square^{\prime} / \square$ interface, nucleation is not required, as it is in the forward transformation. When the activation energy for growth is surmounted (i.e., a sufficiently high temperature is reached during the constant heating rate scans), a cascade begins and each $\square$ ' particle in the cascade path is consumed by the surrounding $\square$ matrix nearly instantaneously. We know the reversion must occur cooperatively, because integrated areas of the sharp peaks observed in DSC scans and the steps observed with dilatometry and resistometry are too large to result from the reversion of a single $\square$ ' particle. Furthermore, the number of $\square$ ' particles that revert far exceeds the number of sharp peaks. Interestingly, if the original forward transformation could become $100 \%$ complete, the reversion process would presumably require nucleation of the $\square$ phase. This might produce a process similar to the forward reaction in which there would be no longer be an opportunity for cascades observed as sharp peaks or steps (i.e., $\square$ 
phase units would still form by individual bursts, but the reversion would not necessarily be cooperative).

\section{Conclusions}

The $\square \rightarrow \square$ ' transformation on cooling and its reversion during heating have been studied in a Pu-2.0 at\% Ga alloy using resistometry, differential scanning calorimetry, and dilatometry. The present work supports the view, as reported in the literature, that the transformation from the fcc $\square$ phase in the Pu-2.0 at\% Ga alloy to the monoclinic \' phase occurs by a martensitic process when alloys are cooled below the ambient temperature. Upon heating, the $\square$ ' reverts to ๑. The martensite burst and the reversion start temperatures range between $-97^{\circ} \mathrm{C}$ and $-145^{\circ} \mathrm{C}$ and $27.4^{\circ} \mathrm{C}$ and $61{ }^{\circ} \mathrm{C}$, respectively. A more detailed examination of the process also confirms that the nature of the transformation involves an isothermal mode during which nucleation appears to be thermally activated but the growth mode occurs in instantaneous bursts. Therefore, nucleation is expected to be the controlling step in the transformation kinetics describing the overall accumulation of the martensite product.

While individual martensitic units are expected to form very rapidly, such individual steps cannot be observed by the techniques employed here. However, it is likely that the overall transformation proceeds by numerous individual bursts occurring nearly simultaneously. During cooling, this effect results in a relatively smooth progression of the transformation as observed in the above techniques.

During heating, on the other hand, the reversion curve shows a succession of very large, periodic, discrete, incremental changes which emphasize more clearly the autocatalytic nature of the reversion process. It is concluded in this paper that the observed periodicity is the result of a 
combination of an interplay between a cooperative autocatalysis of cascades of reversion bursts, and self-quenching caused by small changes of temperature and/or stress accompanying each cascade. The heat of the $\square \square$ ' transformation is estimated to be about $+4.1 \pm 0.2 \mathrm{~kJ} / \mathrm{mole}$.

The ease with which cascades occur during the reversion cycle appears to be connected with the fact that nucleation does not play a major role during the reversion so that the autocatalytic cascades are mainly related to movement of the $\square \square$ ' interfaces as the martensite is consumed by the matrix. In the forward transformation, nucleation difficulties prevent autocatalytic cascade bursts involving many martensite units from occurring.

While the mode of the martensitic transformation, because of its thermally activated nucleation, may be considered to represent isothermal martensite, during both the continuous cooling and heating cycles the transformation may be regarded as consisting of a succession of a step-like progressions of short isothermal holds followed by small changes of temperature. The overall result is an isothermal martensitic product obtained during continuous cooling. If the above qualitative interpretation of the observed periodic bursts is accepted, it should be possible, in principle, to model the $\square$ values by introducing suitable parameters for free energy changes, thermal conductivity, and local stress fields likely to be involved in the $\square \rightarrow \square$ ' transformation.

\section{Acknowledgements}

This work was performed under the auspices of the U.S. Department of Energy by University of California, Lawrence Livermore National Laboratory under Contract W-7405-Eng-48.

Work was performed under the auspices of the U.S. Department of Energy by Los Alamos National Laboratory under contract number W-7405-ENG-36. 


\section{References}

1. D. E. Peterson and M. E. Kassner: Bull. Alloy Phase Diagr., 1988, vol. 9, pp. 261.

2. F. H. Ellinger, C. C. Land, and V. O. Struebing: J. Nucl. Mater., 1964, vol. 12, pp. 226.

3. S. S. Hecker and L. F. Timofeeva: Los Alamos Science, 2000, vol. 26, pp. 244-251.

4. N. T. Chebotarev, E. S. Smotriskaya, M. A. Andrianov, and O. E. Kostyuk: in Plutonium 1975 and Other Actinides, edited by H. Blank and R. Lindner, North Holland Publishing Co., Amsterdam, 1975, pp. 37-46.

5. P. E. A. Turchi, L. Kaufman, Z.-K. Liu, and S. Zhou: Report No. UCRL-TR-206658, Lawrence Livermore National Laboratory, Livermore, CA, September 20, 2004.

6. $\quad$ S. S. Hecker: Los Alamos Science, 2000, vol. 26, pp. 290-335.

7. C. R. Heiple and S. H. Carpenter: Metall. Trans. A, 1992, vol. 23A, pp. 779-783.

8. S. S. Hecker, D. R. Harbur, and T. G. Zocco: Prog. Mater. Sci., 2004, vol. 49, pp. 429485.

9. J. T. Orme, M. E. Faiers, and B. J. Ward: in Plutonium 1975 and Other Actinides, edited by H. Blank and R. Lindner, North-Holland Publishing Company, Amsterdam, 1975, pp. 761-773.

10. D. S. Schwartz, J. N. Mitchell, D. V. Pete, and M. Ramos: JOM-J. Min. Met. Mat. Soc., 2003, vol. 55, pp. 28-30.

11. S. Kitching, P. G. Planterose, and D. C. Gill: in Plutonium Futures-The Science, edited by G. D. Jarvinen, AIP Conference Proceedings, vol. 673, American Institute of Physics, Melville, NY, 2003, pp. 79-81.

12. K. J. M. Blobaum, C. R. Krenn, J. J. Haslam, M. A. Wall, and A. J. Schwartz: in Actinides--Basic Science, Applications, and Technology, edited by L. Soderholm, J. J.

Joyce, M. F. Nicol, D. K. Shuh, and J. G. Tobin, Mater. Res. Soc. Symp. Proc., vol. 802, Pittsburgh, PA, 2003, pp. 33-38.

13. J. N. Mitchell, M. Stan, D. S. Schwartz, and C. J. Boehlert: Metall. Mater. Trans. A, 2004, vol. 35A, pp. 2267-2278.

14. J. J. Haslam, M. A. Wall, D. L. Johnson, D. J. Mayhall, and A. J. Schwartz: in Electrically Based Microstructural Characterization III, edited by R. A. Gerhardt, A. P. Washabaugh, M. A. Alim, and G. M. Choi, Mater. Res. Soc. Symp. Proc., vol. 699, Pittsburgh, PA, 2002, pp. 295-300.

15. G. Hakvoort and C. M. Hol: J. Therm. Anal. Calorim., 1999, vol. 56, pp. 717-722.

16. T. F. J. Pijpers, V. B. F. Mathot, B. Goderis, R. L. Scherrenberg, and E. W. van der Vegte: Macromolecules, 2002, vol. 35, pp. 3601-3613.

17. K. J. M. Blobaum: Lawrence Livermore National Laboratory, Livermore, CA, unpublished research, 2005.

18. G. V. Kurdjumov and L. G. Khandros: Dokl. Akad. Nauk SSSR, 1949, vol. 66, pp. 211.

19. A. Borgenstam and M. Hillert: Acta mater., 2000, vol. 48, pp. 2777-2785.

20. R. F. Bunshah and R. F. Mehl: T. Am. I. Min. Met. Eng., 1953, pp. 1251-1258.

21. R. E. Cech and J. H. Hollomon: T. Metall. Soc. AIME, 1953, vol. 197, pp. 685-689.

22. C. R. Heiple and S. H. Carpenter: J. Nucl. Mater., 1987, vol. 149, pp. 168-179.

23. M. Grujicic, H. C. Ling, D. M. Haezebrouck, and W. S. Owen: in Martensite: A Tribute to Morris Cohen, edited by G. B. Olson and W. S. Owen, ASM International, Materials Park, OH, 1992, pp. 175-196.

24. H. Pops and T. B. Massalski: T. Metall. Soc. AIME, 1964, vol. 230, pp. 1662-1668. 
25. R. Brook and A. R. Entwisle: J. Iron Steel I., 1965, vol. 203, pp. 905-912.

26. A. R. Entwisle: Metall. Trans., 1971, vol. 2, pp. 2395-2407.

27. V. Raghavan: in Martensite: A Tribute to Morris Cohen, edited by G. B. Olson and W. S. Owen, ASM International, Materials Park, OH, 1992, pp. 197-225.

28. E. S. Machlin and M. Cohen: T. Am. I. Min. Met. Eng., 1951, vol. 191, pp. 746-754.

29. J. K. Lee, Y. Y. Earmme, H. I. Aaronson, and K. C. Russell: Metall. Trans. A, 1980, vol. 11, pp. 1837-1847.

30. H. R. Gardner: in Plutonium Handbook: A Guide to the Technology, edited by O. J. Wick, vol. I, The American Nuclear Society, La Grange Park, IL, 1967, pp. 59-100.

31. C. R. Krenn, M. A. Wall, and A. J. Schwartz: in Actinides--Basic Science, Applications, and Technology, edited by L. Soderholm, J. J. Joyce, M. F. Nicol, D. K. Shuh, and J. G. Tobin, Mater. Res. Soc. Symp. Proc., vol. 802, Pittsburgh, PA, 2003, pp. 9-14.

32. D. S. Schwartz: Santa Fe, NM, private communication, 2004.

33. N. Onoda, T. Matsuo, and H. Suga: Phil. Mag. A, 1988, vol. 57, pp. 245-260.

34. Plutonium Handbook: A Guide to the Technology, vol. 1, edited by O. J. Wick, American Nuclear Society, La Grange Park, IL, 1980.

35. CRC Handbook of Chemistry and Physics, edited by D. R. Lide, CRC Press, Boca Raton, 1992.

36. R. E. Cech and D. Turnbull: T. Am. I. Min. Met. Eng., 1956, vol. 206, pp. 124-132.

37. A. Borgenstam: Mat. Sci. Eng. A-Struct., 1999, vol. A273-275, pp. 425-429. 


\section{Figure Captions}

Figure 1a: The Pu-Ga phase diagram proposed by Western researchers. This diagram is generally used as a "working" diagram..$^{1-3}$

Figure 1b: The Pu-Ga phase diagram proposed by Russian researchers. ${ }^{3,4}$

Figure 2: Pu-Ga constrained equilibrium diagram. The area between the $M_{b}$ and $R_{s}$ lines is the region where metastable $\square$ ' forms upon cooling from the $\square$ phase. The $M_{b}$ and $R_{s}$ lines also show how the transformation hysteresis varies with composition. Data points (open circles) are from reference 8 .

Figure 3: Normalized resistance of a Pu-2.0 at\% Ga alloy during seven thermal cycles at $1.5^{\circ} \mathrm{C} / \mathrm{min}$. The increase in resistance at $-123^{\circ} \mathrm{C}$ corresponds to the start of the martensitic transformation to the $\square$ ' phase and is termed martensite burst $\left(M_{b}\right)$. Similarly, the decrease in resistance beginning at $32^{\circ} \mathrm{C}$ is the reversion of $\square$ ' to the $\square$ phase (reversion start, $R_{s}$ ).

Figure 4: Cooling portions of DSC thermograms showing the $\square \rightarrow \square$ ' transformation in a $\mathrm{Pu}-2.0$ at $\% \mathrm{Ga}$ alloy. The $\square$ ' phase begins to form at $-97^{\circ} \mathrm{C}$ (at $1.5^{\circ} \mathrm{C} / \mathrm{min}$ ), where a negative deviation from the baseline is observed (note that in these cooling scans the chronological progression of the scan is from right to left). (a): Unsubtracted (raw) data with the data offset along the $y$-axis for clarity. Note that the exothermic peak does not return to the baseline, indicating that the transformation is not complete at $-160^{\circ} \mathrm{C}$. (b): Data with a baseline subtracted from the raw data. Peak shapes are somewhat distorted due to the background subtraction.

Figure 5: Heating portions of DSC thermograms showing the $\square$ ' $\rightarrow \square$ reversion in a $\mathrm{Pu}-2.0$ at $\%$ Ga alloy. Reversion begins at $33^{\circ} \mathrm{C}$ (at $20^{\circ} \mathrm{C} / \mathrm{min}$ ) and is evidenced by a periodic series of sharp endothermic peaks. Note that these sharp peaks are more evident at the slower 
cooling rates. (a): Unsubtracted (raw) data. (b): Data with a baseline subtracted. In both (a) and (b), data have been offset along the $y$-axis for clarity.

Figure 6: Resistometry data showing the $\square$ ' $\rightarrow \square$ reversion on heating. In the undifferentiated data (top), small discrete incremental changes (steps) in the resistance corresponding to the reversion are evident. In the differentiated data (bottom), a distinct periodic series of spikes is present in the reversion temperature range. The dotted line indicates the location of the baseline. Figure 7: Dilatometry traces through the $\square^{\prime} \rightarrow \square$ reversion in a Pu-2 at\% Ga alloy. The top plot shows the length change $(\% d \mathrm{~L} / \mathrm{L})$ through the reversion and the lower plot depicts the same traces as a function of $d \mathrm{~L} / d($ time $)(\% / \mathrm{min})$. Note that the discrete incremental length changes in the upper graph are depicted as spikes in the lower graph and that slower heating rates enhance these features.

Figure 8: DSC heating scan at $5^{\circ} \mathrm{C} /$ min showing the numbering scheme and the periodicity of the sharp peaks The tallest peak is designated peak 0 , and the period, $\square$, is the distance (in ${ }^{\circ} \mathrm{C}$ ) between peaks.

Figure 9: Period $(\square)$ of the $\square^{\prime} \rightarrow \square$ reversion bursts in a Pu-2.0 at\% Ga alloy. DSC data are shown in (a) and data from dilatometry $(d \mathrm{~L} / \mathrm{L})$ and resistometry $(\square)$ are shown in (b). In (a), $\square$ values from three DSC scans at $1.5^{\circ} \mathrm{C} / \mathrm{min}$ are plotted to show an approximation of the scatter. Note that the majority of the burst periods observed with DSC, dilatometry, and resistometry fall within this range $\left(1.5\right.$ to $\left.4.5^{\circ} \mathrm{C}\right)$, regardless of heating rate, or technique.

Figure 10: Finite-element map of the normal stress field surrounding an $\square$ ' particle which has reverted to the $\square$-phase. The stress field accelerates reversion in front of the reverted particle and decelerates the reversion in regions perpendicular to it. The zero-stress contour is dashed. 


\section{Evidence of transformation bursts during thermal cycling of a Pu-Ga alloy}

KJM Blobaum, ${ }^{1}$ CR Krenn, ${ }^{1}$ JN Mitchell, ${ }^{2}$ JJ Haslam, ${ }^{1}$ MA Wall, ${ }^{1}$ TB Massalski, ${ }^{3}$ AJ Schwartz ${ }^{1}$

${ }^{1}$ Lawrence Livermore National Laboratory, Livermore, CA 94550

${ }^{2}$ Los Alamos National Laboratory, Los Alamos, NM 87545

${ }^{3}$ Carnegie Mellon University, Pittsburgh, PA 15213

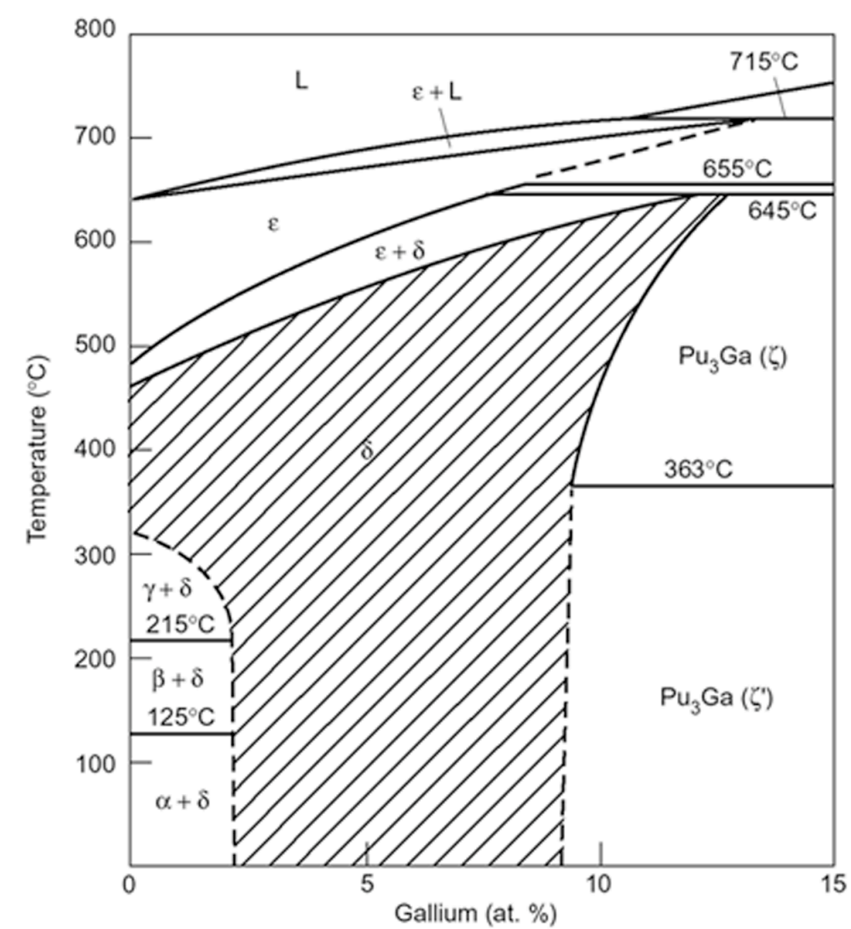

Figure 1a: The Pu-Ga phase diagram proposed by Western researchers. This diagram is generally used as a "working" diagram. ${ }^{1-3}$

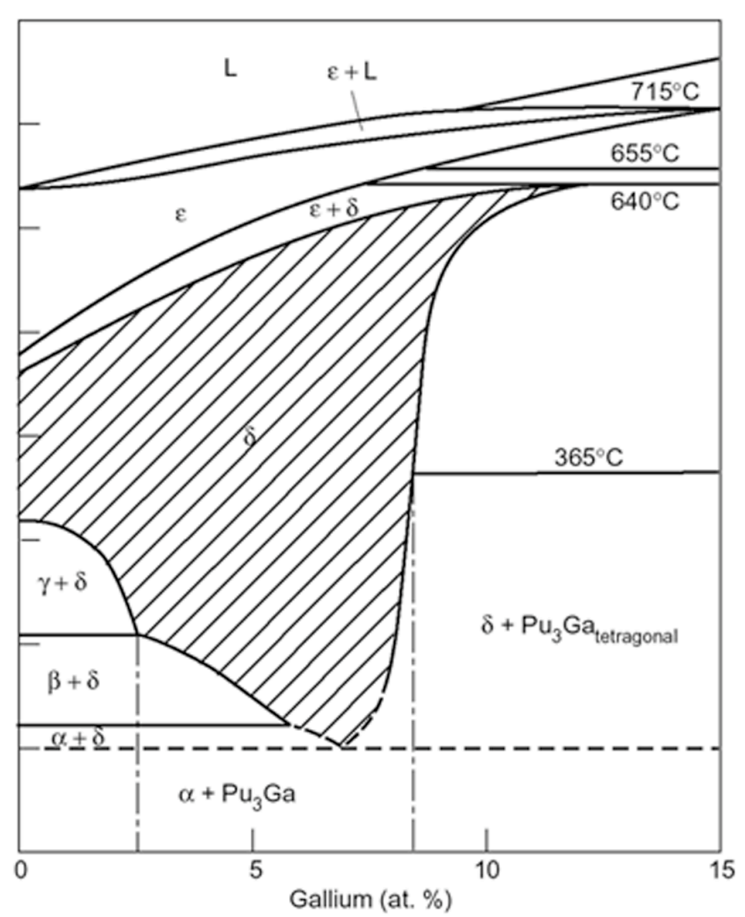

Figure 1b: The Pu-Ga phase diagram proposed by Russian researchers. ${ }^{3,4}$ 


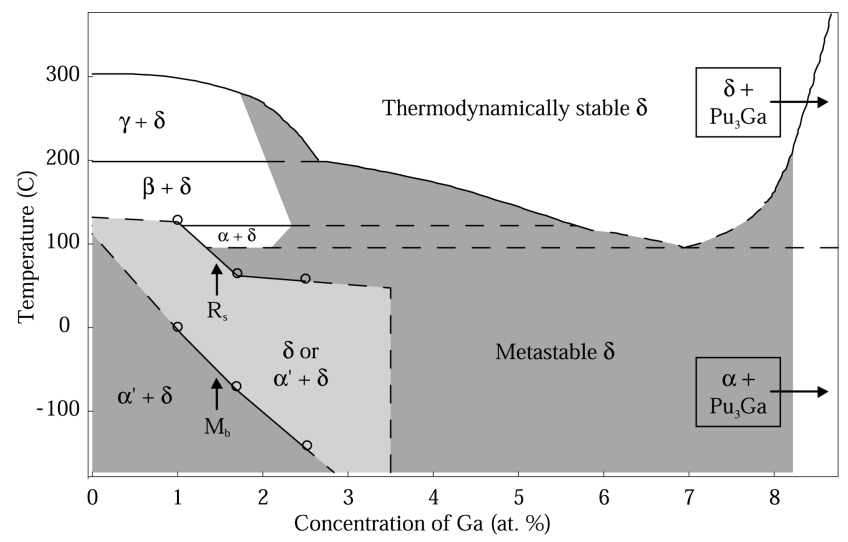

Figure 2: Pu-Ga constrained equilibrium diagram. The area between the $M_{b}$ and $R_{s}$ lines is the region where metastable $\square$ ' forms upon cooling from the $\square$ phase. The $M_{b}$ and $R_{s}$ lines also show how the transformation hysteresis varies with composition. Data points (open circles) are from reference 8 . 


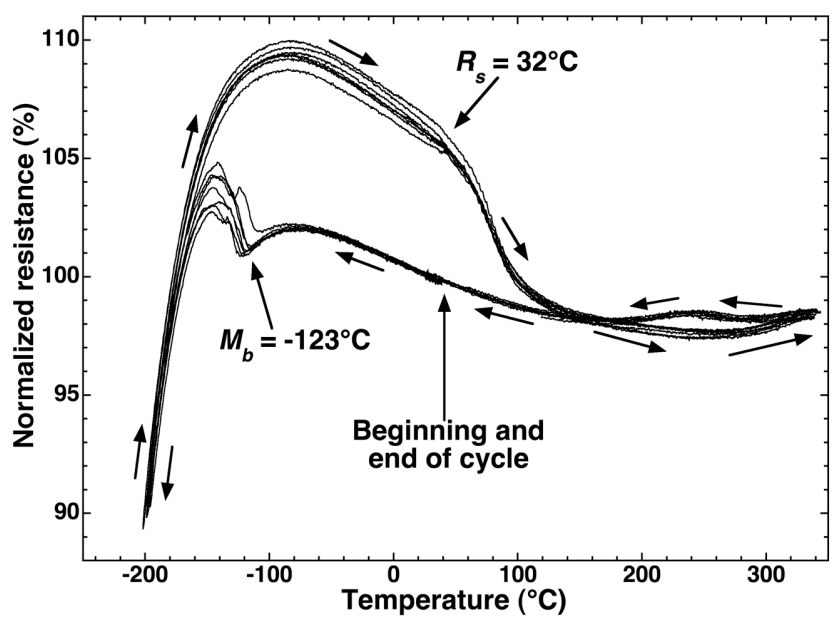

Figure 3: Normalized resistance of a Pu-2.0 at $\%$ Ga alloy during seven thermal cycles at $1.5^{\circ} \mathrm{C} / \mathrm{min}$. The increase in resistance at $-123^{\circ} \mathrm{C}$ corresponds to the start of the martensitic transformation to the $\square$ ' phase and is termed martensite burst $\left(M_{b}\right)$. Similarly, the decrease in resistance beginning at $32^{\circ} \mathrm{C}$ is the reversion of $\square$ ' to the $\square$ phase (reversion start, $R_{s}$ ). 
a.

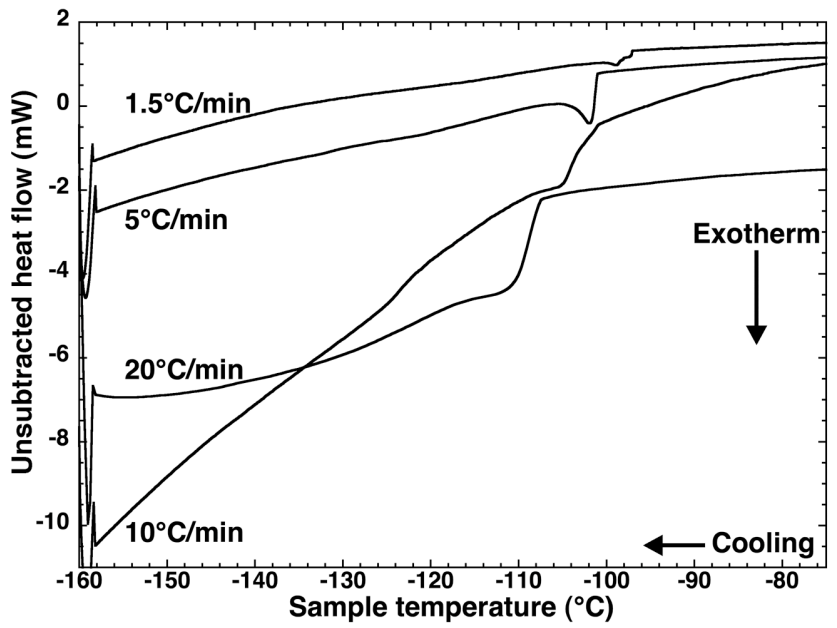

b.

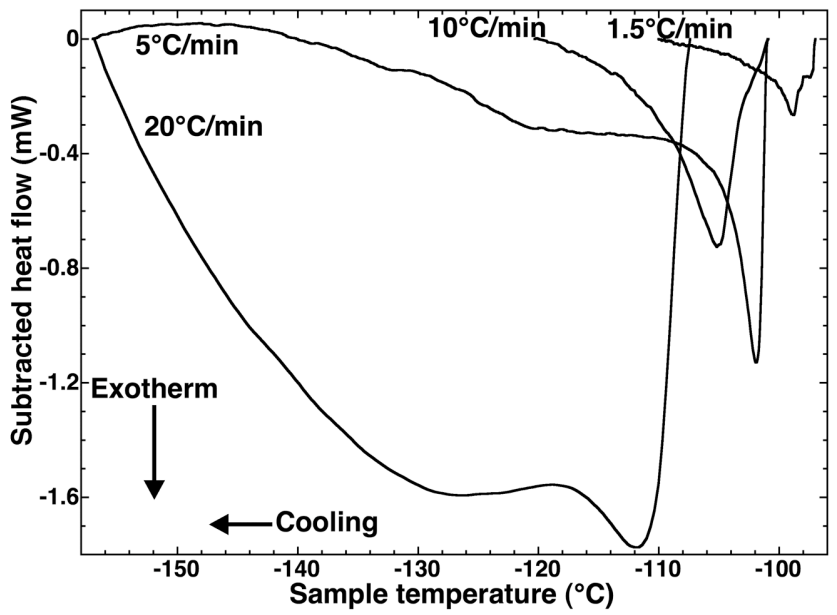

Figure 4: Cooling portions of DSC thermograms showing the $\square \rightarrow \square$ ' transformation in a $\mathrm{Pu}-2.0$ at $\% \mathrm{Ga}$ alloy. The $\square$ ' phase begins to form at $-97^{\circ} \mathrm{C}$ (at $1.5^{\circ} \mathrm{C} / \mathrm{min}$ ), where a negative deviation from the baseline is observed (note that in these cooling scans the chronological progression of the scan is from right to left). (a): Unsubtracted (raw) data with the data offset along the $y$-axis for clarity. Note that the exothermic peak does not return to the baseline, indicating that the transformation is not complete at $-160^{\circ} \mathrm{C}$. (b): Data with a baseline subtracted from the raw data. Peak shapes are somewhat distorted due to the background subtraction. 
a.

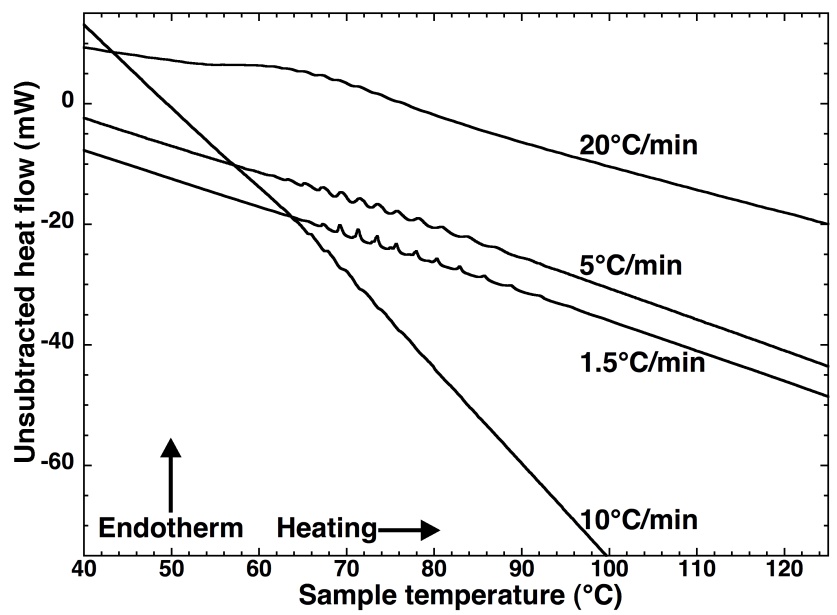

b.

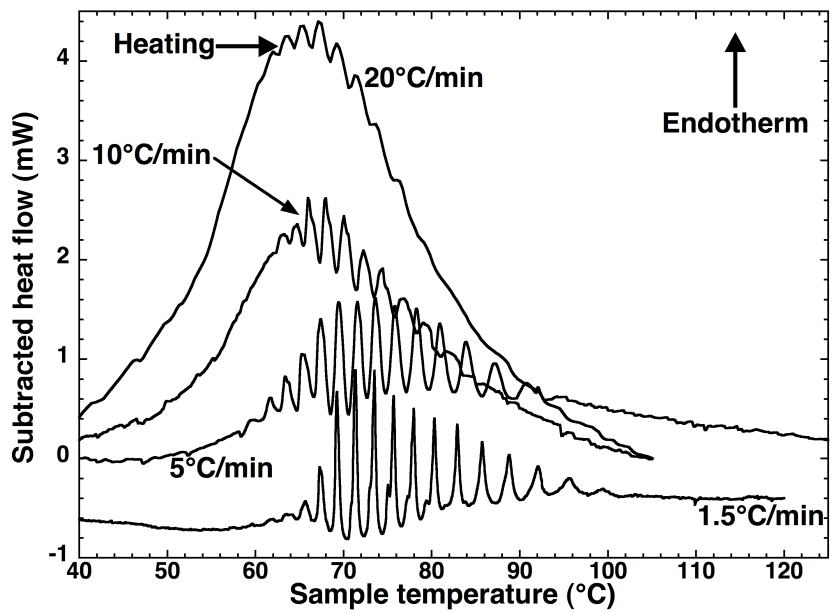

Figure 5: Heating portions of DSC thermograms showing the $\square^{\prime} \rightarrow \square$ reversion in a $\mathrm{Pu}-2.0$ at $\%$ Ga alloy. Reversion begins at $33^{\circ} \mathrm{C}$ (at $20^{\circ} \mathrm{C} / \mathrm{min}$ ) and is evidenced by a periodic series of sharp endothermic peaks. Note that these sharp peaks are more evident at the slower cooling rates. (a): Unsubtracted (raw) data. (b): Data with a baseline subtracted. In both (a) and (b), data have been offset along the $y$-axis for clarity. 


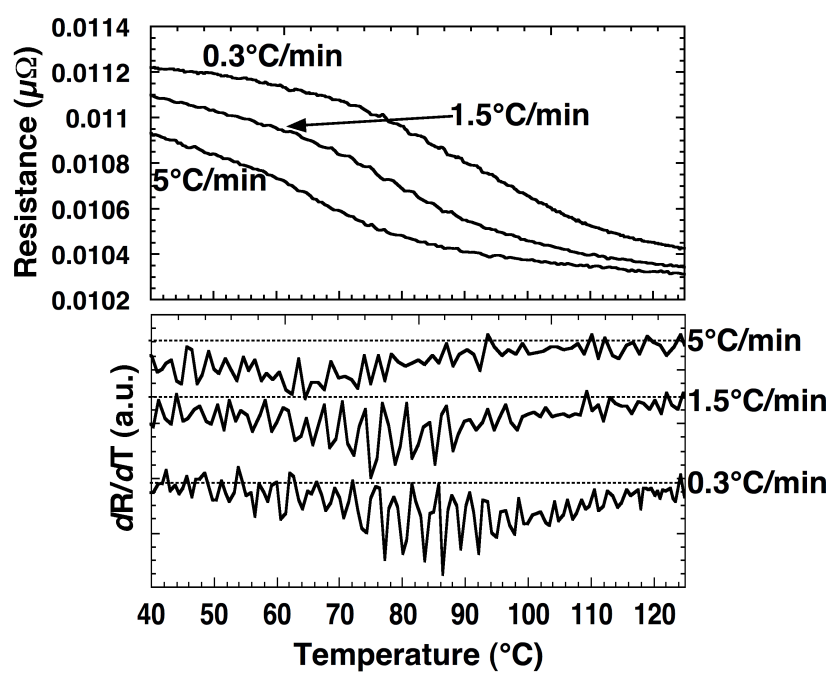

Figure 6: Resistometry data showing the $\square$ ' $\rightarrow \square$ reversion on heating. In the undifferentiated data (top), small discrete incremental changes (steps) in the resistance corresponding to the reversion are evident. In the differentiated data (bottom), a distinct periodic series of spikes is present in the reversion temperature range. The dotted line indicates the location of the baseline. 


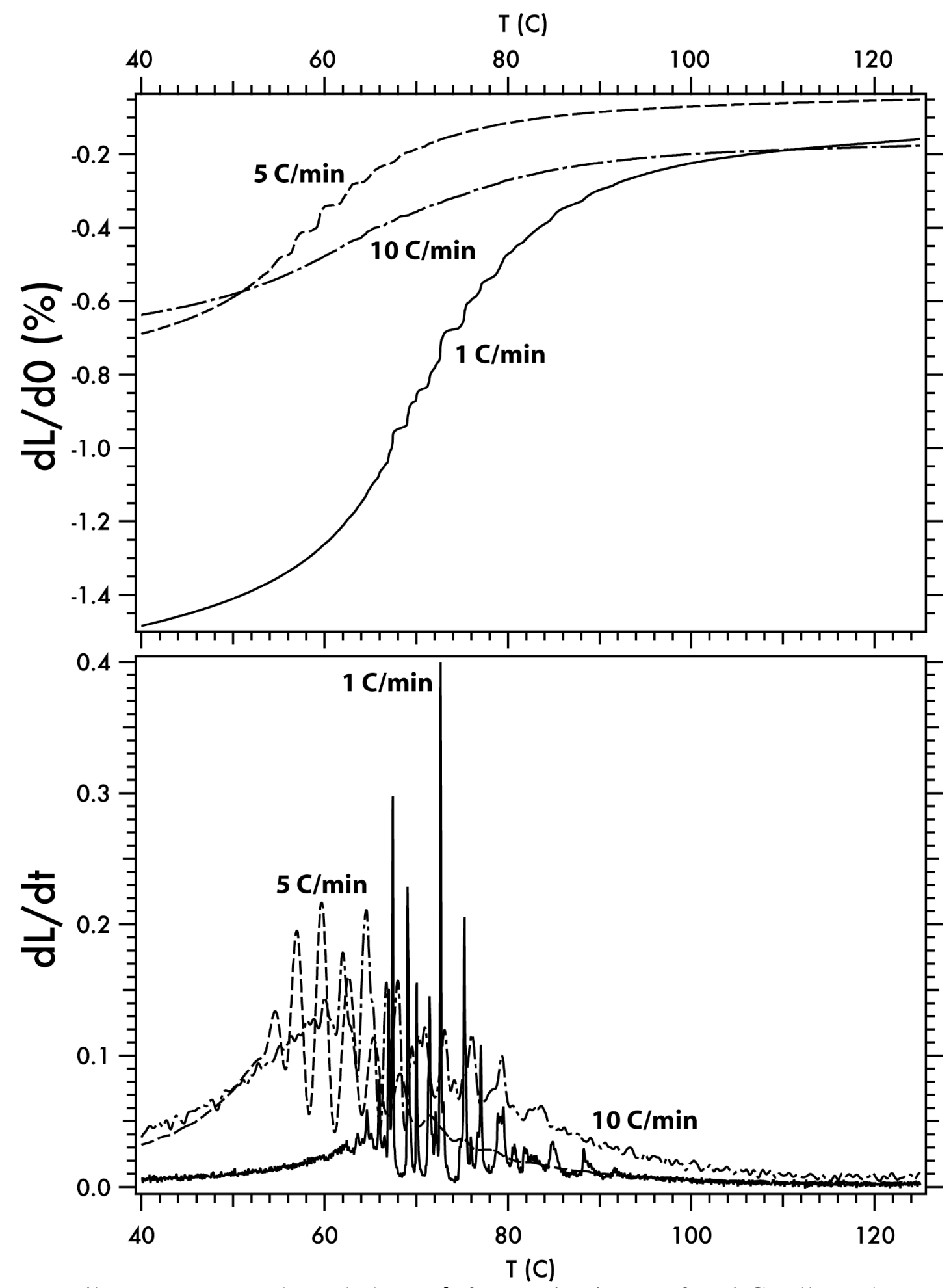

Figure 7: Dilatometry traces through the $\square^{\prime} \rightarrow \square$ reversion in a Pu-2 at\% Ga alloy. The top plot shows the length change (\%dL/L) through the reversion and the lower plot depicts the same traces as a function of $d \mathrm{~L} / d(\mathrm{time})(\% / \mathrm{min})$. Note that the discrete incremental length changes in the upper graph are depicted as spikes in the lower graph and that slower heating rates enhance these features. 


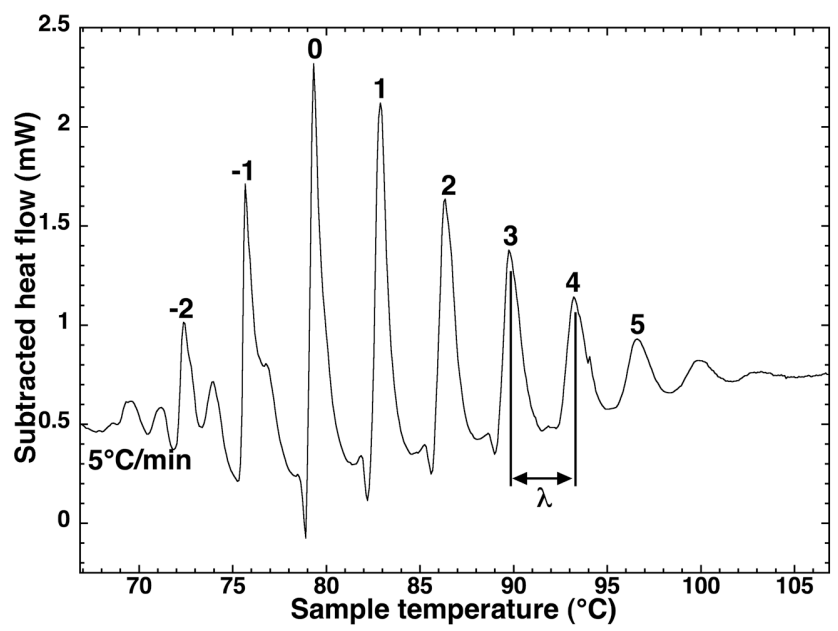

Figure 8: DSC heating scan at $5^{\circ} \mathrm{C} / \mathrm{min}$ showing the numbering scheme and the periodicity of the sharp peaks The tallest peak is designated peak 0 , and the period, $\square$, is the distance (in ${ }^{\circ} \mathrm{C}$ ) between peaks. 
a.

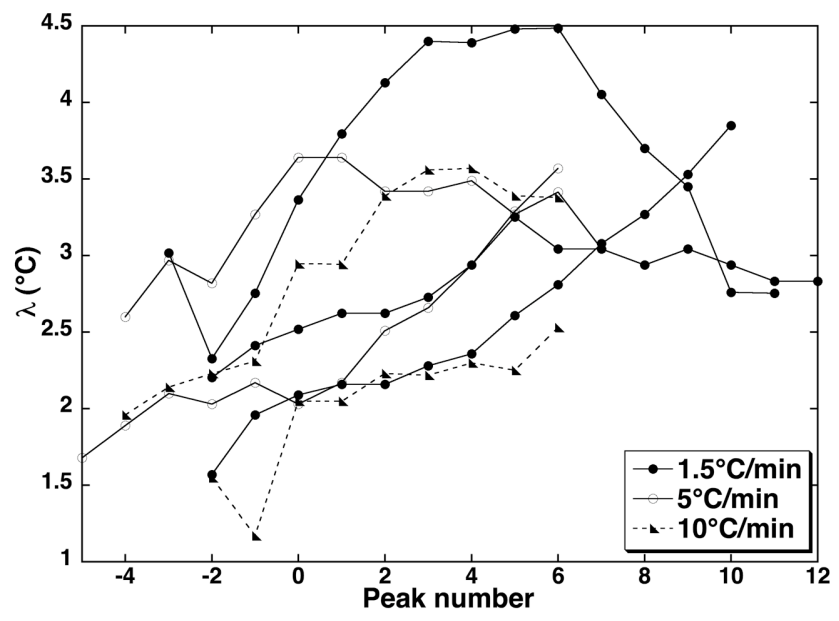

b.

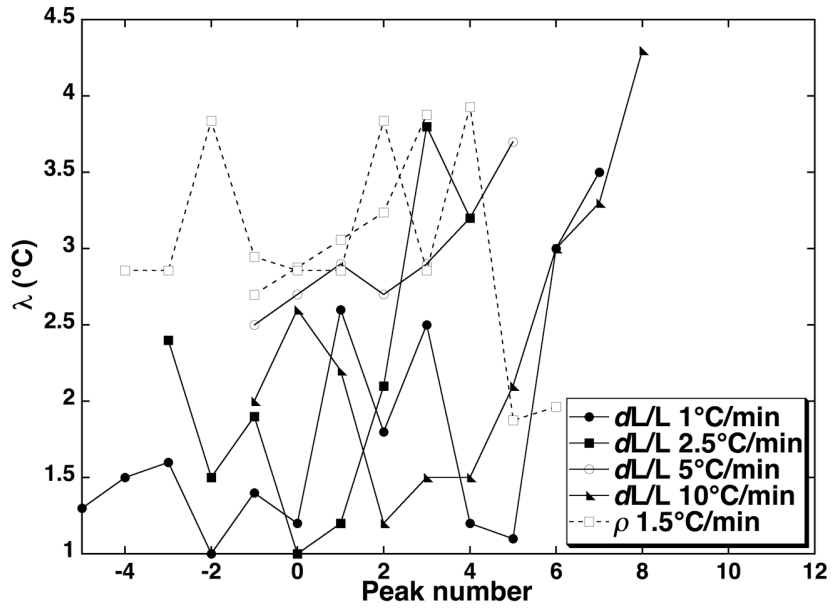

Figure 9: Period ( $\square$ ) of the $\square$ ' $\rightarrow \square$ reversion bursts in a Pu-2.0 at\% Ga alloy. DSC data are shown in (a) and data from dilatometry $(d \mathrm{~L} / \mathrm{L})$ and resistometry ( $\square$ ) are shown in (b). In (a), $\square$ values from three DSC scans at $1.5^{\circ} \mathrm{C} / \mathrm{min}$ are plotted to show an approximation of the scatter. Note that the majority of the burst periods observed with DSC, dilatometry, and resistometry fall within this range $\left(1.5\right.$ to $\left.4.5^{\circ} \mathrm{C}\right)$, regardless of heating rate, or technique. 


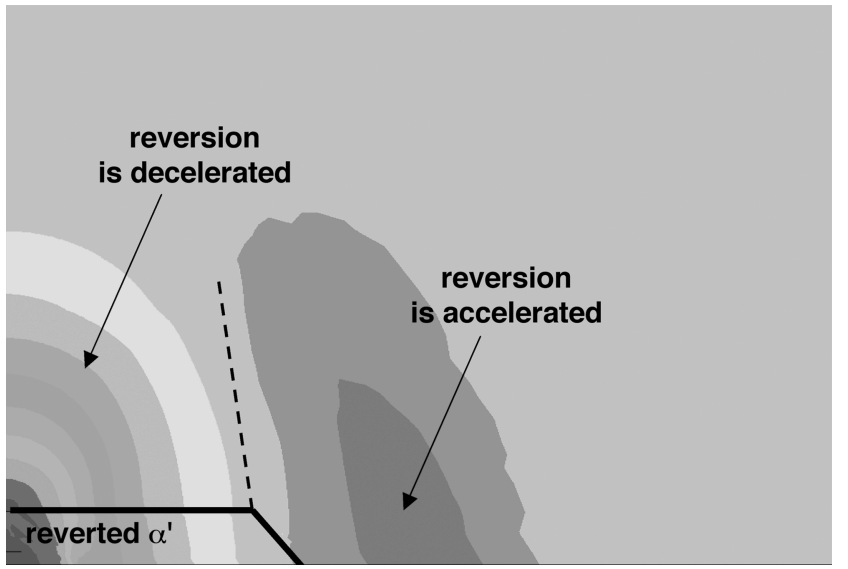

Figure 10: Finite-element map of the normal stress field surrounding an $\mathrm{D}$ ' particle which has reverted to the $\square$-phase. The stress field accelerates reversion in front of the reverted particle and decelerates the reversion in regions perpendicular to it. The zero-stress contour is dashed. 